desde la academia

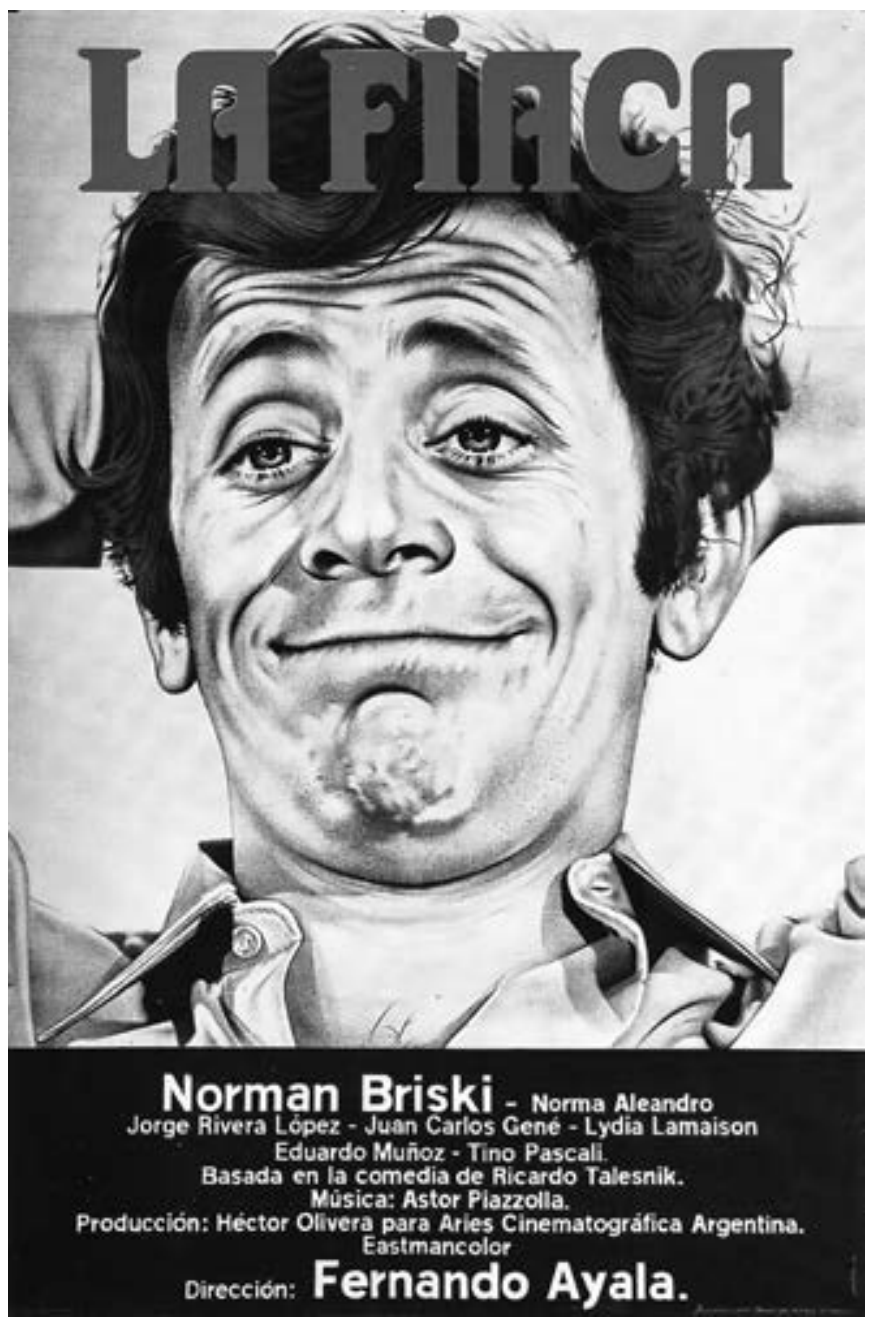

\title{
Un teatro y un cine para el gran público. Accesibilidad y síntesis estilística en la versión fílmica de La fiaca (Fernando Ayala, 1969)
}

Theater and Cinema for the general public. Accessibility and stylistic synthesis in the film version of La fiaca (Fernando Ayala, 1969)

http://dx.doi.org/10.22235/d.v0i26.1324

Jorge Sala 


\section{RESUMEN}

El artículo se propone analizar la traslación fílmica, dirigida por Fernando Ayala, de la obra teatral La fiaca, escrita por Ricardo Talesnik. Se busca construir un recorrido doble: por un lado, el estudio de las coincidencias entre los proyectos creativos del director y el dramaturgo, y la importancia de los factores económicos que incidieron en algunas de las elecciones estéticas. Por otro lado -y a partir de una metodología de análisis comparado sobre las estrategias de puesta en escena teatrales y cinematográficas- el trabajo pretende trazar los rasgos singulares que el filme establece con relación a la obra original y con otras producciones de la década del sesenta. Como eje articulador entre ambos aspectos se indaga el rol que cumplió la noción de accesibilidad como mecanismo que permitió ampliar la repercusión masiva de la película. Este mayor alcance se basó fundamentalmente en la recuperación del actor protagónico de la pieza original: Norman Briski.

Palabras clave: cine argentino, transposición, factores económicos, accesibilidad, años sesenta

\section{Introducción}

Tras el golpe militar que desplazó a Juan Domingo Perón de su segunda presidencia en 1955, se abrió un proceso de transformaciones que afectó prácticamente a todos los ámbitos de la producción cultural argentina. En lo referido al cine, el colapso de los grandes estudios cinematográficos y la progresiva disolución del modelo clásico-industrial de producción funcionaron como fenómenos internos entrelazados de forma invariable con la conflictividad que se vivía en el espectro político y artístico en general.

En el marco de esta época, que puso en evidencia una abierta crisis de la hegemonía (Gramsci, 1930/1981), se consolidaron las trayectorias de dos realizadores que prefiguraron, con sus películas y declaraciones, la renovación cinematográfica de la década siguiente. Leopoldo Torre Nilsson y Fernando Ayala fueron los fundadores de esta modernización, como señalara el entonces crítico Tomás Eloy Martínez (1961): “entendidas como punto de partida para un cine argentino distinto, sus obras parecen implicar, así no solo un cambio sino también una profecía” (p. 14).
ABSTRACT

The article aims to analyze the film directed by Fernando Ayala based on the play La fiaca by Ricardo Talesnik. It seeks to build a double bind: Firs, studying the coincidences between the creative projects of the director and the playwright and the importance of the economic factors that influenced some of the aesthetic choices. Second, based on a methodology of comparative analysis on staging strategies, both theatrical and cinematographic, the work goals to trace the unique features that this film establishes in relation to the play and other productions of the sixties. As an articulating axis between both aspects, an inquiry is made around the role fulfilled by the notion of accessibility as a fundamental mechanism that made possible an amplification of the massive repercussion of the proposal, based fundamentally on the recovery of the protagonist Norman Briski

Keywords: Argentinean cinema, adaptation, economic factors, accessibility, sixties

En cierto modo antitéticos, ambos realizadores encarnaron los rumbos venideros. Torre Nilsson optó por la autoconciencia narrativa hacia un cine de arte e intelectual, por la visibilidad internacional de sus producciones, con una clara predilección por el realismo subjetivo. Mientras tanto, Ayala tendió a privilegiar lo testimonial (aun cuando apeló a unas alegorías para remitirse al contexto), a prestar atención a los aspectos comerciales -sin renunciar entender al cine como arte industrial-y, por ende, a supeditar los intereses autorales en beneficio de la ampliación de los potenciales espectadores de sus películas.

Aunque a primera vista el cine moderno que ellos iniciaron pareció inclinarse hacia el lado de Torre Nilsson, no es menos cierto que Ayala también cumplió un papel fundamental dentro de este proceso. Como el propio director recordaría con humor años más tarde: "dicen que Torre Nilsson fue el padre de la Generación del 60; me conformo con que digan que soy el tío" (citado en España, 2005, p. 109).
Jorge Sala

Consejo Nacional de Investigaciones Científicas y Técnicas. Universidad de Buenos Aires, Buenos Aires, Argentina jorgesala82@hotmail.com

Recepción: 20/02/2017 Aceptación: 05/05/2017 
El 6 de marzo de 1969, Ayala estrenó la traslación a la gran pantalla de la obra teatral La fiaca, de Ricardo Talesnik, dada a conocer dos años antes. Como una obra tardía dentro del cine moderno, esta versión se recorta como una síntesis de las búsquedas emprendidas por ambos miembros de aquella familia cinematográfica de los sesenta.

La pieza presenta la historia de Néstor Vignale, empleado modelo de la empresa Fiagroplast que, un día, sin otra excusa que padecer de fiaca (pereza frente a una tarea), decide no ir a trabajar. Lo inexplicable de su conducta genera toda una serie de desencuentros en su entorno familiar y laboral. Apelando al tono humorístico, Talesnik muestra los avatares de una rebelión individual que, a medida que se desarrollan las acciones, va encerrando al protagonista hasta derrotarlo.

La película optó simultáneamente por la reflexión y el entretenimiento, materializando así una voluntad de construcción artística personal sumada al deseo de captación del gran público, así como la primacía de la subjetividad mixturada con el testimonio del entorno. Lo hizo apelando a un texto comprometido no solamente por su tema, cercano al universo del espectador medio, sino también por el empleo de procedimientos basados en la "desfamiliarización que hace que un hecho cotidiano automatizado por la rutina se vuelva extraño, y por consiguiente susceptible a cuestionamientos" (Miller, 2014, p. 678). El filme condensó, además, varias de las elecciones estéticas y narrativas de las que se valió tradicionalmente el cine local de la época al momento de adaptar una obra teatral. El presente trabajo busca estudiar este proceso de reescritura.

\section{Metodología}

Debido a que se trata de un caso singular -tanto por las cuestiones inmanentes propuestas, pero también por el sentido comercial basado en el conocimiento previo de los espectadores sobre la exitosa obra teatral- el análisis debe atender los aspectos textuales así como las condiciones externas que acompañaron el proceso de su confección y difusión.

Optar por un estudio semiótico-comparativo entre la obra fuente y su reelaboración, sin considerar al público como un factor dinamizador o a los elementos coyunturales que incidieron en el proceso, impedirá ver de qué manera varias de las decisiones estéticas de la película estuvieron motivadas por el propósito de alcanzar a grandes sectores que operó desde siempre como sello identitario de la producción de Ayala. Colocar el foco en ciertos factores económicos puestos en juego en el proceso evitará caer en un error común, tal como apunta María Eugenia Mudrovcic (2010):

Negar el efecto que el dinero trae al juego de intercambios simbólicos, pretendiendo actuar como si lo económico configurara una dimensión o una lógica ajena, externa a la lógica que rige la cultura, y a la que solo es posible aludir si se la disfraza, o se la eufemiza" (p. 14).

Si este es un problema crucial dentro de la literatura latinoamericana, tema sobre el que enfocan las reflexiones de Mudrovcic, lo es todavía más en una práctica industrial y bastante más costosa como lo es la de cualquier emprendimiento cinematográfico. La amalgama sólida entre las contribuciones artísticas y las miras puestas en el impacto en la platea que tuvo La fiaca deben, por tanto, ser consideradas de forma complementaria para comprender algunas decisiones escénicas y de producción que acompañaron el trasvase de la obra del escenario a la pantalla.

En este sentido, el artículo se organiza sobre tres ejes: en primer lugar, se observa la cercanía de los proyectos creativos del autor de la pieza original (Talesnik) con el horizonte postulado por el cineasta. Contrastar algunas declaraciones permitirá comprobar cómo la existencia 
de afinidades electivas ayudó a que su encuentro fuera productivo. Asimismo, recobrando las discusiones entre el cine de expresión frente al cine de entretenimiento, así como las posturas de Leopoldo Torre Nilsson y Fernando Ayala, se buscará reconstruir una genealogía de los debates de los años cincuenta y sesenta que tienen un claro eco dentro de la formulación artística de La fiaca.

En segundo lugar, se plantea la importancia de la accesibilidad (entendida como alcance) propia del medio cinematográfico. En tanto arte de masas, el cine llega con comodidad a un número de potenciales espectadores mayor que cualquier experiencia teatral. En la facultad de tornar asequible el espectáculo radica una de las razones de su trasvase y, al mismo tiempo, aparecen indicios sobre las razones de la repercusión que tuvo el filme. El análisis de esta cuestión permitirá comprender algunas elecciones formales, originadas en el interés por ensanchar el número de receptores.

En tercer lugar, se presenta un estudio interno de la película con relación a la pieza original, para demostrar de qué manera dichas elecciones articulan una síntesis de las opciones estéticas y narrativas desarrolladas por el cine moderno argentino de los sesenta toda vez que este se valió de puestas teatrales contemporáneas. En este sentido, la película constituye una suerte de destilado quintaesencial de las prácticas cinematográficas de la época.

En La fiaca, la tendencia a la desteatralización de las formulaciones de partida se da la mano con su vertiente antagónica: la sobreteatralización. A partir de esta interacción dinámica entre estrategias enfrentadas, los mecanismos de la puesta en escena adoptan características particulares. A su vez, el relato propone también una tensión entre el encierro teatral que domina los tramos iniciales de la película y la apertura de los espacios, la circulación y el vagabundeo que predominan en la segunda parte. Por último, al realismo de las situaciones, a su costumbrismo interesado en retomar un dilema típico de la clase media urbana de ese momento, se le adhiere un afianzamiento de lo artificioso que obtiene sus puntos más altos de efervescencia en el desmontaje sistemático de algunos temas a través de procedimientos cinematográficos y en la actuación rocambolesca de Norman Briski, protagonista tanto de la película como de la obra teatral.

De todo lo anterior se desprende cuál será la perspectiva metodológica aplicada en este estudio. El examen inmanente sobre la intertextualidad (Barthes, 1974; Kristeva, 1978) será complementado con un enfoque atento a las condiciones de producción de dicha relación. En tal sentido, la teoría de los polisistemas de Patrick Cattrysse (1992) permite abordar el objeto de manera interrelacionada, tanto desde lo textual como desde su dimensión pragmática. José Antonio Pérez Bowie (2003), siguiendo esta línea, resume la necesidad de "plantear las cuestiones que conciernen a la adaptación en su contexto de llegada y, por otro, debe examinarse cuáles son los mecanismos sistemáticos que han determinado el proceso transformacional de la adaptación" (p.15).

\section{La tensión entre lo comercial}

y la emergencia del cine de autor

En los primeros párrafos que Tomás Eloy Martínez (1961) dedica al estudio de la obra de Ayala y Torre Nilsson en tanto que iniciadores del camino de la modernización en Argentina, aparece una caracterización que resume los intereses del primero de estos nombres:

Su limitación más grave es el cuidado que pone para equilibrar dentro de cada film los factores industriales y artísticos, y si bien desde 1958 -cuando comienza a ser su propio productor- esa preocupación se vuelve menos explícita, hay muchas declaraciones suyas en los 3 años previos que inducen a ver en ella un rasgo importante de su temperamento (p. 15). 
En su condición de crítico interesado en los rasgos innovadores que empezaban a transformar el panorama del cine argentino, Martínez conjuga en su comentario las dos líneas en pugna al interior de la crisis de la hegemonía mencionada al principio. Torre Nilsson definió al viejo esquema de producción en decadencia como cine de espectáculo, opuesto a la corriente emergente, de la que él mismo formaba parte, denominada cine de expresión. En palabras de David Oubiña:

En el primero el director se limita a ordenar los elementos del rodaje como parte de una maquinaria industrial que lo excede mientras que, en el segundo, participa de todas las etapas de la realización y el film se convierte en una obra de creación personal (Oubiña, 2016, p. 350).

Martínez, situado claramente dentro de uno de los bandos en pugna, considera problemático este doble interés, como si se tratara de dos realidades imposibles de conciliar. Sin embargo, su definición precoz reconoce no solo el proyecto creativo del cineasta, sino también el de Aries, la productora que fundó en 1958 junto a Héctor Olivera. Bajo un aforismo atribuido a René Clair: "el mejor cine posible para la mayor cantidad posible de espectadores" (citado en Rapallo, 1993, p. 6)”, Aries en general y Ayala en particular construyeron un camino en el cual podían coexistir pacíficamente un intelectual como David Viñas -en la escritura de los guiones de las primeras obras que dio a conocer la firma ${ }^{1}-$ con comedias livianas o películas dedicadas a explotar la figura de actores reconocidos como Luis Sandrini.

El debate que gravita alrededor de la diferencia entre la opción por el espectáculo o por la expresión se vincula al papel de los directores entendidos como autores, y al cine en su condición de arte. En un artículo originalmente publicado en 1959, Torre Nilsson desarrolla sus ideas sobre esta cuestión, en las que conjuga una variante personal de la teoría del autor que significó un parteaguas dentro de la modernización fílmica de la posguerra:

Es evidente que la posición más recomendable para aquel que quiera crear dentro del cine es la del director, pero también es cierto que pueden existir directores artesanos y directores creadores, aun cuando dudo que de los primeros quede historia alguna (Torre Nilsson, 1985, p. 54).

Esta toma de posición implica una clara estrategia de subversión, de herejía (Bourdieu, 1992) contra el modelo industrial previo basado, según esta mirada, en el predominio de obras rodadas por cineastas eficaces que subsumían su labor a los emprendimientos de los grandes estudios que los contrataban. Como indica Raymond Williams (1994), en estos casos "la producción para el mercado implica la concepción de la obra de arte como una mercancía, y la del artista, por más que él se defina de otra forma, como una clase particular de productor de mercancías" (p. 41).

Frente a esta situación, Torre Nilsson denunciaba en 1952, en un texto sintomáticamente titulado El cine que enfurece a las multitudes, a aquellos que tratan

de convertir al cine en una píldora digestiva al gusto que no es siquiera el de una auténtica ambición popular dictaminada por algunos sujetos que andan entristeciendo al cine del mundo con la misma eficacia con que podían habernos envenenado fabricando embutidos; pero con un terrible agravante: mientras la venta de embutido en estado de descomposición está penada por la ley, la fabricación de películas letales no encuentra oposiciones de ninguna índole, contando con el inconsciente apoyo de las multitudes y el aplauso crítico de los que las sugieren como necesarias (Reproducido en Torre Nilsson, 1985, p. 25). El candidato (1959) 
La virulencia de los términos empleados da cuenta, por un lado, del carácter subversivo que adquiere la distinción entre la adscripción hacia la preminencia del espectáculo - asociada a la búsqueda de un rédito comercial- y el camino de la expresión, afianzado en la idea de construcción personal (autoral). Por otro lado, estos campos semánticos presuponen un escenario que, en palabras de Antonio Gramsci (1930/1981), puede definirse como una encrucijada crítica en la que "lo viejo muere y lo nuevo no acaba de nacer” (p. 37). Un momento de crisis, pero también de clara expansión en el que, como apunta Williams (1994), los productores artísticos buscan definir posiciones o, en sus palabras, "intentos posteriores de definición entre formas 'comerciales' y otras formas ('creativas', 'auténticas') de la misma práctica manifiesta” (p. 47).

Teniendo en cuenta estos aspectos, pueden comprenderse mejor las críticas recibidas por el proyecto artístico-económico de Fernando Ayala, en el marco de un cine que pretendió dejar atrás las perspectivas industriales para abrazar la emergencia de una modernización autoral vernácula.

\section{Las afınidades electivas}

En sus primeros años como director, Ayala logró conectar su voluntad de construir un cine de llegada masiva con relatos que no renegaban del valor de la novedad en los temas y del trabajo sobre la puesta en escena fílmica. ${ }^{2}$ Sin embargo, en la segunda mitad de los sesenta, se consolidó su inclinación hacia el cine de espectáculo. La fiaca vendría a ocupar una posición equidistante en este panorama, como síntesis dialéctica que reunió ambos términos, es decir, la valoración artística conjugada con el reaseguro que implicaba valerse de un suceso comercial para multiplicarlo.

Desde su estreno en el Teatro del Sur, en Buenos Aires, el 29 de setiembre de 1967, la obra de Ricardo Talesnik se convirtió en un enorme éxito que acaparó la atención del público en su paso por la cartelera porteña. Dos semanas antes, la obra había inaugurado su trayectoria pública en Santiago de Chile, con un elenco independiente bajo la dirección de Jaime Celedón. La versión porteña fue dirigida por Carlos Gorostiza y contó con un reparto encabezado por Norman Briski. La repercusión que la obra alcanzó en Argentina, más aún tomando en cuenta que se trataba de un autor prácticamente desconocido, condujo a que Aries decidiera no solamente comprar los derechos de la obra sino contratar a Talesnik como guionista. ${ }^{3}$

En una entrevista concedida a la revista española Primer Acto, con motivo del arribo de su texto a los escenarios madrileños, Talesnik postulaba una serie de ideas que conforman el núcleo de su pensamiento sobre las especificidades de La fiaca con relación al teatro argentino producido en ese momento. El texto, recogido en Dubatti (1989), brinda algunas pistas para comprender el pensamiento del autor al intentar reflexionar sobre el carácter innovador de su propuesta dentro del magma teatral circundante. Siguiendo esta premisa, comienza afirmando:

\begin{abstract}
Me preocupa el hombre como ser social, el hombre en su relación con el medio y con los otros hombres. Ahora bien, gran parte de los principales problemas de la clase media ya han sido llevados a la escena mediante procedimientos 'naturalistas' (citado en Dubatti, 1989, p. 159).
\end{abstract}

Refiriéndose luego al absurdo y a las líneas de crueldad inspiradas en los trabajos "del Living Theatre, del Action Theatre y de los otros 'Theatre”" (p. 159), Talesnik concluye:

Respeto estas tentativas a nivel de experimentación, pero opino que no producen resultados coherentes, orgánicos. Destinadas a un público muy especial, se encuentran muy lejos, según mi criterio, del camino para acceder a un teatro "para mucha gente".
2:: El ejemplo más logrado en este sentido fue Paula cautiva (1963), un filme que significó, asimismo, la manifestación del encuentro más cercano entre la estética de Ayala y la de Torre Nilsson. Basada en el cuento "La representación", de Beatriz Guido -guionista y pareja de Torre Nilson-, Paula cautiva reunía la denuncia del presente, propia de Ayala, con el examen de una clase dominante en decadencia, cercana al universo de la dupla de creadores de filmes como La casa del ángel (1957) y La mano en la trampa (1961).

3:: La fiaca de Ayala generó, a su vez, un filme en episodios, construido con algunas coincidencias con la anterior y protagonizado por Briski - La guita, (Ayala, 1970)-, y una secuela espuria -iYo también tengo fiaca! (Cahen Salaberry, 1978). Asimismo, la popularidad de Norman Briski en la pantalla se tradujo en otros trabajos gestados dentro del mismo sello productor, en los que el actor tuvo libertad para desatar su reconocida y aplaudida veta histriónica: Psexoanálisis (1968) y Los neuróticos (1971), ambas dirigidas por Héctor Olivera. 
De modo que yo, enfrentado a la necesidad de expresar teatralmente un tema que me interesa, siento que la realidad debe ser mi punto de partida; pero la llegada será un punto $\mathrm{X}$, un punto donde se opera una síntesis entre los elementos realistas (contenido, personaje, lenguaje) y el enfoque aportado por mi visión particular y teniendo en cuenta siempre que el teatro es, ante todo (aqui me animo a pontificar) espectáculo (citado en Dubatti, 1989, p. 159; cursivas añadidas).

Por su parte, Fernando Ayala dejaba traslucir su inclinación por un cine antintelectual cuando sostenía, refiriéndose a las películas de principios de los sesenta: "estoy en desacuerdo con ese cine que alguna vez se hizo en el país, demasiado intelectual, en clave, del que por suerte nos hemos apartado" (citado en Rapallo, 1993, p. 37). Entre el deseo de edificar películas para "la mayor cantidad posible de espectadores" y la intención de Talesnik de formular "un teatro para mucha gente", los proyectos creativos de ambos artistas encontraron un punto de confluencia productivo que se inició con la versión fílmica de La fiaca.

Más en profundidad, la postura defendida tanto por el autor como por el director estuvo asociada a cómo abandonar las marcas del realismo behaviorista -visiblemente agotadas a finales de la década del sesenta- para conseguir unos espectáculos que, sin dejar de testimoniar algunos temas caros al universo referencial inmediato, hallaran otros mecanismos de enunciación diferentes al de la captación de trozos de vida. El resultado partió, en ambos casos, de una desnaturalización de situaciones cotidianas, banales, puestas en cuestión a través de una eficaz mixtura entre lo subjetivo y lo metarreflexivo, disfrazado bajo aspectos lúdicos. Bajo la creencia compartida en el papel central que el humor debía jugar dentro del proceso, se buscó acercar al mayor número de espectadores.
En todo caso, la consecuencia de este encuentro fue la ampliación de los efectos buscados por ambas partes: a partir de esta película, Talesnik inició una prolífica carrera como guionista cinematográfico; Ayala, a su vez, recondujo, aunque puntualmente, su carrera como director hacia cierto compromiso por expresar la inmediatez, al valerse de una obra que conjugaba en partes iguales las cualidades artísticas de su factura con unas perspectivas comerciales ya probadas en su paso por los escenarios.

En un sentido más amplio, La fiaca implicó para su autor - prácticamente un desconocido, que había alcanzado notoriedad en el teatro- la instalación definitiva en el campo artístico y la consecuente profesionalización. Y para Aries significó la apertura al terreno de la distribución ${ }^{4}$, además de su ya probada trayectoria como firma productora. Al iniciarse en este rubro, la empresa creció hacia otras zonas de la economía cinematográfica, y pasó a encargarse de la comercialización de películas de cineastas argentinos (Juan José Jusid, María Herminia Avellaneda, Luis Puenzo) y de títulos internacionales, algunos de los cuales alcanzaron amplia resonancia. ${ }^{5}$

Sin lugar a dudas, el espaldarazo recíproco que supuso esta alianza estuvo amparado en la existencia de una perspectiva común acerca de la propia práctica. Este sustrato podría ser definido como una creencia compartida en los valores del espectáculo en su doble acepción: tanto la que servía a los cineastas modernizadores de los sesenta para vilipendiar los productos comerciales -bajo el mote de "cine de espectáculo"-, y que Ayala defendió, como aquella que para Talesnik aparecía en su citada declaración sobre la idea de entretenimiento. En el horizonte de ambos creadores, las apuestas encaminadas a obtener un acercamiento masivo a los espectadores fue un factor esencial. Y el cine, por sus propias particularidades técnicas, ayudó a alcanzar esta meta conjunta y multiplicarla de forma exponencial. 
El cine, un arte asequible

La traslación a la pantalla de La fiaca debe entenderse como una operación en la cual la accesibilidad es uno de sus fundamentos centrales. El suceso de la puesta teatral se hallaba restringido -como sucede con toda experiencia escénica concreta- a un único espacio y tiempo. Podían montarse versiones de la pieza -como de hecho se hicieron, sobre todo gracias a la rápida difusión del texto dramático-, pero estas poseían diferencias con aquella que había alcanzado notoriedad. Esta situación se tornaba algo paradójica: mientras se engrosaba el público potencial, a través de la difusión de la pieza, de las críticas favorables o de otros mecanismos de promoción, la obra se encontraba limitada para expandir su campo de acción, algo que solamente lograría el cine.

Según Anxo Abuín González (2012), “desde el punto de vista de los estudios culturales, el concepto de accesibilidad es fundamental para delimitar algunas opciones en los procesos de adaptación fílmica” (p. 66). Si bien este autor analiza los casos en los que algunos textos dramáticos de Shakespeare fueron reelaborados filmicamente con vistas a ser consumidos (digeridos) por el gran público, a partir de una simplificación o actualización de sus contenidos, también es necesario tomar en cuenta el modo en que lo específicamente escénico incide dentro de las decisiones de un director cinematográfico al momento de fijar estos elementos mediante la captación de la cámara y su manipulación posterior a través del montaje.

Si bien el teatro tiene como rasgos característicos la copresencia y la simultaneidad entre espectáculo y espectador -que determinan la cualidad no expansible de este arte-, el cine se caracteriza, por el contrario, por su posibilidad de multiplicación. En esta capacidad propagadora reside lo que aquí se denomina accesibilidad. No se trata solo de una transformación técnica -determinante, por otra parte, para que la onda expansiva de una película alcance lugares recónditos con mayor facilidad que una puesta teatral-; su capacidad de difusión también se vincula con el propio lugar del medio, entendido como arte de masas, frente a una disciplina como el teatro que, más allá de las intenciones demostradas por un dramaturgo y un elenco, se instalan en el terreno de lo legitimado (Bourdieu, 1991).

Siguiendo las ideas de Raymond Williams (1994), el cine -al igual que otros medios como la radio o la televisión y en general todos los dispositivos reproductibles- "constituyen sistemas de acceso directo, al menos en el sentido en que son culturalmente accesibles dentro del desarrollo social normal, sin ninguna forma de adiestramiento cultural” (p. 103). En definitiva, es esta condición no mediada por un saber culto, sumada a su capacidad propagadora, la que define la accesibilidad del medio.

Osvaldo Pellettieri (1997) afırma que una de las razones que hicieron que la versión teatral de La fiaca se convirtiera en un enorme suceso popular se debió, en gran medida, a la intervención de Norman Briski en el papel de Néstor Vignale. Cabe destacar que esta elección originalmente no formó parte del pensamiento de Talesnik sobre la materialización de su obra, sino que fue el resultado de una mediación con el director (Gorostiza). El impacto causado en la platea cuando finalmente se estrenó la pieza, lo llevaron a cambiar radicalmente de opinión. Talesnik recordaba:

Briski me parecía un mimo, un actor divertido pero que no respondía a mi idea del personaje. No era el porteño tipo. Yo no creía en él, y como no vi los ensayos anteriores, me morí de angustia cuando vi el ensayo general. ¿Qué cagada!, me dije, pensando que era mi debut y despedida en el teatro. Briski parecía un loco suelto, recién liberado, pero todavía no curado. Me agarré la cabeza y pensé ya entregado: ¿Quién se va a identificar, quién se va a reír con él? Al día siguiente ya reconocía que estaba equivocado" (citado en Pellettieri, 1997, p. 138). 
Con mayor énfasis que en otros casos de reescrituras de piezas teatrales estrenadas a lo largo de los sesenta, en La fiaca lo fundamental del teatro, la puesta en escena, apareció como un elemento que el cine buscó recobrar. Las maniobras empleadas para lograrlo apuntaron al mismo tiempo a dejar una huella de la experiencia espectatorial de quien asistía a las funciones teatrales -fundamentalmente la referida al desempeño del actor principal- y a reproducir al infinito unas acciones que en los escenarios hubieran quedado subsumidas obligatoriamente al aquí y ahora de la representación.

En la recuperación de Briski como protagonista, la película buscó tornar cercano para un número de asistentes aún mayor aquello que se mantenía acotado al público teatral de Buenos Aires. La repercusión que el actor había logrado con su personaje fue un factor central sobre el que descansó el proyecto de Ayala. Esta intención se constata al revisar los afiches promocionales y todo el dispositivo gráfico - press books, programas de mano, fotogramas colocados en las marquesinas de los cines-, basados en su mayoría en la imagen en primer plano del intérprete. Entonces, gracias a la accesibilidad aportada por el filme, un espectador de zonas distantes a Buenos Aires podía experimentar lo que la crítica teatral había dado en llamar el auténtico "festival Briski" (Potenze, 1967) sin tener que esperar a que la obra saliera de gira y llegara a su lugar de residencia o estar obligado a trasladarse para apreciar aquello que se comentaba en las revistas, en la televisión y en el relato de terceros.

El intento de expandir el alcance de una puesta ya exitosa a un espectro más amplio provocó que, en gran medida, los lineamientos centrales de la versión teatral fueran sostenidos en la reescritura fílmica. Esto fue evidente en el caso del desempeño del actor protagónico, aunque no corrió la misma suerte el resto del elenco, que fue reemplazado en su totalidad.
Por otra parte, con la llegada de la película se buscó que el montaje teatral quedara en un segundo lugar, ante la novedad que implicaba la película. Una cláusula del contrato firmado entre Talesnik y Ayala prohibía que la obra se representara al mismo tiempo que la película se hallaba en rodaje. La determinación contractual produjo algunas quejas por parte de los actores que no fueron incluidos en ella ("Prohibida La fiaca", 19696), al tiempo que puso de manifiesto la decisión de Aries de asegurarse el grueso de los beneficios al hacer asequible la propuesta.

\section{La sintesis entre desteatralización \\ y sobreteatralización}

Entre las modalidades de intersección textual entre el teatro y el cine propuestas por Jacques Gesternkorn (1994), la modelización y el reciclaje constituyen dos formas específicas. La primera se verifica cuando procedimientos típicamente identificados como propios de una puesta en escena teatral aparecen en el engranaje del filme de manera indirecta, es decir, cuando no se trata de la captura lisa y llana de un espectáculo. De acuerdo con la definición de modelización, ciertas opciones de trabajo con el espacio y el tiempo, así como algunas acciones de los personajes, de los movimientos de los actores o ciertos desenvolvimientos de la trama, pueden ser emparentados con el teatro, aunque, dado su carácter elusivo, su reconocimiento depende de la competencia del público.

Por el contrario, el reciclaje implica un intento deliberado de disolver los componentes que provienen de los escenarios en función de su adopción a una retórica cinematográfica. Esta modalidad, a diferencia de aquellos casos en los que la filiación interdisciplinar emerge como marca evidente, "tiende a atenuar la teatralización de los filmes, ocultándola” (Abuín González, 2012, p. 72).

Esta clasificación, atenta a dar cuenta de relaciones no necesariamente transpositivas, se relaciona con dos estrategias que los cineastas han puesto en práctica al 
momento de enfrentarse a una obra anterior: la sobreteatralización y la desteatralización (Aumont, 2012, p. 16).

[Se trata] de dos grandes extremos entre los que se han de mover las estrategias disponibles para un director de cine que quiera llevar un drama escrito a la pantalla: tratar la acción con la intención de preservar en lo posible su naturaleza teatral... o incorporar al drama todo el potencial visual cinematográfico, creando nuevas relaciones entre el actor y el decorado, el espacio y el tiempo, así como la manera de presentación ante el público (Abuín González, 2012, pp. 67-68).

Las traslaciones de piezas teatrales concretadas por los directores pertenecientes al cine moderno argentino de los sesenta estuvieron siempre inclinadas hacia alguna de las dos variantes en detrimento de la otra. Hasta el estreno de La fiaca no había exponentes de un tipo de relato que hiciera visible la potencialidad de cruzar ambas opciones. Por el contrario, las películas -y los directores en sus declaraciones-delimitaban explícitamente el modo de relacionarse con la teatralidad del momento. Ya sea porque apuntaban a privilegiar un tipo de construcción realista - reñida, en consecuencia, con la franca asunción de lo artificioso que supone la sobreteatralización- o bien porque procuraban evidenciar que sus elecciones de puesta en escena procedían de una fuente reconocida, los directores no se permitieron explorar los bordes ni generar fricciones. ${ }^{7}$

En el caso de La fiaca, la existencia de elementos antitéticos conjugados en función de la concreción de una unidad estaba presente ya en la pieza original. Pellettieri (1997) se refiere al texto de Talesnik como un modelo de realismo híbrido (p. 135). En él se conservan aún procedimientos emparentados con la dramaturgia de principios de los sesenta -basada en una idea de captación cuasi fotográfica de los acontecimientos que eludía la aparición de lo antinaturalista- pero estos son mixturados con otros que abren la senda hacia un territorio nuevo, sin instaurar todavía una forma distinta a la precedente.

Una crítica sobre la película publicada en La Nación -en la que se hace explícita esa condición bifásicaobservaba esta particularidad de la versión escénica original como un primer escollo que tuvo que afrontar la traslación fílmica:

El primer problema que Fernando Ayala debió resolver fue el de la necesidad de optar por una de las dos líneas narrativas que se alternan a lo largo de la pieza de Talesnik; una de tono realista directo, que prevalece en todo el primer acto; la otra, de clara implicancia alegórica, visible en toda la segunda parte y en el desenlace de la comedia. Ayala y Talesnik no vacilaron en la elección: el film está enteramente "jugado" en la primera de esas orientaciones, o sea con un sostenido acento realista, sin apelaciones al lenguaje alegórico (salvo lo que pueda tener de alegoría la obra toda, en su propuesta contra una sociedad alienante y opresora, y salvo también alguna metáfora visual oportunamente intercalada, que no quiebra la fluidez ni el tono naturalista del relato) (“Versión fílmica bien lograda”, 1969).

Aunque el comentario reconoce la existencia de elementos dispares, lo innovador de la película -como lo fue en su momento la puesta teatral- estriba, contrariamente a lo que allí se afirma, en su negación a optar por un camino preestablecido. La mezcla del registro costumbrista con una abierta artificiosidad ocasiona que ambos polos exhiban sus puntos de confluencia y operen bajo una lógica en la que la sobreteatralización y la desteatralización se entrelazan, y difuminan las barreras que antes las separaban.
7:: Entre los filmes que optaron por la desteatralización pueden mencionarse $\mathrm{El}$ crack (Martínez Suárez, 1960) y Los de la mesa 10 (Feldman 1960); la veta contraria aparece en dos traslaciones dirigidas por René Mugica: El centroforward murió al amanecer (1961) y El reñidero (1965). 
Una poética de la mezcla

Ya en la primera secuencia de la película queda instaurado el juego tensional entre opuestos que recorrerá la totalidad del relato. En un espacio ostensiblemente neutro, semejante a un escenario provisto solo de un mobiliario mínimo (una cama, una mesa de luz con un velador, un reloj despertador, un cuadro decorativo), Néstor Vignale y su mujer, Marta (Norma Aleandro), se disponen a dormir. Recuperando punto por punto los movimientos del prólogo de la puesta original -los gestos titubeantes de Néstor alrededor de la alarma del despertador-, Ayala les introduce una variación: después de apagar la luz, los créditos avanzan y la imagen teatral del principio va modificándose en función de las elipsis marcadas por el paso de las horas en el reloj. Antes de finalizar los títulos, cuando se menciona que la película fue rodada en los estudios Lumiton, la imagen se traslada de forma repentina al exterior de un edificio de departamentos. A esta imagen la sucede otro plano de una construcción moderna, que conduce al interior de una oficina vacía.

La planificación de la secuencia, vertebrada en torno a unos planos que rodean a la pareja, devela el espacio desde su condición de lugar elaborado de manera artificial. Frente al reconocimiento de que se trata de un ámbito intencionalmente reproducido en estudio - lo que lo acercaría a la escenografía elaborada para una puesta teatral $-^{8}$ el salto del interior al plano del edificio a cielo abierto provoca un primer punto de choque que determina el tono que asumirá el resto de la puesta en escena fílmica. Entre el subrayado de lo teatral de los primeros minutos y su cuestionamiento, a través de la inclusión de exteriores y unas marcadas elipsis, se establece el carácter oscilante de las elecciones del cineasta.

Una vez introducido este esquema basado en la discordancia, resulta coherente -dentro del verosímil propuesto por la película desde el inicio- que el realismo costumbrista que predomina en la primera parte se vea horadado por instancias antirrealistas que modifican o intensifican sus sentidos. En la puesta teatral, las actitudes corporales de Briski servían como instrumento para desnaturalizar una serie de comportamientos $\mathrm{y}$ transformarlos en acciones maquinales, en tópicos. Discutiendo con Marta sobre su deseo de hacer fiaca, de quedarse en cama, Vignale encadena verbal y gestualmente un conjunto de movimientos que componen su rutina agobiante de empleado de oficina:

NÉSTOR: -iOchocientos treinta y dos pesos!... Tengo que levantarme por ochocientos treinta y dos pesos!... Lavarme la cara con agua fría, afeitarme, hacerme la corbata, meterme en el subte o colgarme de un colectivo, mirar los coches de los demás, pasar delante de las vidrieras, saludar sonriendo a un tipo que no tragás, aguantarme la cargada del ascensorista... itodo por ochocientos treinta y dos pesos!... No, no vale la pena (Talesnik, 1967, p. 9).

Ayala transforma el discurso del protagonista en una sucesión de imágenes que reproducen literalmente aquello que en el teatro permaneció solo verbalizado y representado en escena por el actor mediante la mímica. Como complemento de la expansividad gestual intransferible de Briski, el montaje rápido y la velocidad anormal con la que se encadenan los planos provocan un efecto risible que, al mismo tiempo que se afianza en el artificio, deja traslucir el carácter repetitivo de las situaciones. Con este tratamiento, que deconstruye los tópicos al mostrar su condición de operaciones infinitamente reiteradas, Ayala rompe con el costumbrismo y se burla de él, por lo que establece una distancia irónica frente a la realidad.

El empleo de recursos que tienden a literalizar los enunciados teatrales mediante las imágenes se repite en varias secuencias, sobre todo en los primeros tramos del 
relato. En la puesta de Gorostiza, las virtudes de mimo del actor principal permitían traer a la escena, aunque fuera solo mediante la alusión de las actitudes corporales que apoyaban la palabra, distintas profesiones que conformaban el universo idealizado e inalcanzable del trabajador de clase media. La versión cinematográfica, por su parte, adhiere al cuerpo del protagonista una serie de aditamentos de vestuario y utilería que, junto a la mutación de los espacios, logra ensanchar el efecto cómico mediante la yuxtaposición de lugares y posturas físicas. El color grisáceo de las paredes de la habitación -que imitaba los tonos dominantes de la escenografía teatralcontrasta con el colorido de las escenas fantaseadas. Con un montaje sincopado, Vignale ocupa en un tramo breve de la narración los roles de médico, albañil, vendedor de helados, periodista, al tiempo que desenmascara lo prototípico de estas figuraciones tradicionales.

Además de conectar instantes dispares bajo un denominador común, los recuentos verbales del personaje ocasionan que la puesta en escena quede articulada siempre alrededor de los desempeños de Vignale. En un sentido más profundo, que hace a la modalidad de representación a la que esta película adscribe, la inclusión de estos procedimientos le permite apartarse del realismo behaviorista, torciendo el relato desde lo costumbrista-fotográfico hacia una zona en la que la inclusión de los recuerdos, las fantasías y los sueños de Vignale hacen prevalecer la subjetividad en la construcción del mundo representado.

Mientras en los tempranos sesenta toda una corriente del cine renovador argentino asociado al realismo se afianzó en los valores de una descripción autoconsciente, pero, no obstante, "objetiva” - plagada de elipsis y vacíos narrativos, de tiempos muertos y cuerpos deambulado sin rumbo-, en la película de Ayala las características innovadoras son superpuestas a otras en las que prima la emergencia del trazado fílmico de la fantasía. Siguiendo lo señalado por Domènec Font (2002) para el caso eu- ropeo, en La fiaca "la ruptura moderna se produce a través de una reflexión sobre la narración y sus falsos valores objetivos y en un repliegue hacia la interioridad y la conciencia de lo imaginario" (p. 68). Como consecuencia de esa elección, los elementos visuales muestran el pasaje de la realidad materialmente gris del empleado modelo hacia el estallido en tecnicolor de sus deseos recónditos.

El discurso del protagonista, actualizado en imágenes por el director, denuncia la mecanización que preside las acciones de los oficinistas de clase media.

Como gesto de impugnación de un ritual, la fiaca de Vignale propicia la desarticulación de los movimientos de sus compañeros de trabajo a través de su descripción minuciosa. La escena denuda un sistema en el que hasta las necesidades del cuerpo tienen asignado su turno preciso:

NÉSTOR: Las diez y media... (Piensa, se inquieta, pero se pone a disfrutar.) Di Crocce debe estar levantándose para ir al baño. El Negro lo tiene de punto. (Imitando) “Ché, riñón, vas a cumplir con la patria?”... La Bertone se muere de risa... ¡bah, ella siempre se ríe!... Peralta le dice de usted... Pobre Peralta, tan respetuoso, tan educado, tan limpito... (Decae.) Están todos sentados, cada uno en su escritorio... (Sobreponiéndose.) ¡En cambio yo!... ¡Aquí me tenés, acostado como un bacán!... (Se mira.) En pijama, bien cómodo, tranquilito!... (Otra vez abatido.) Le tiene un terror a la Chancha... (Talesnik, 1967, p. 16).

El relato continuo del personaje hace ingresar no solamente la fantasía, sino también el exterior al espacio doméstico en el que se desarrolla la ficción. Si en la puesta de Gorostiza los movimientos del actor facilitaban la alusión a la extra-escena ubicada más allá de los límites de la habitación, en el filme los raccontos ocasionan que la puesta abandone la inmovilidad de la 
cama en la que Vignale rememora y fantasea sobre su suerte y la de los demás, y se traslade a otros lugares. Imaginarios algunos -cuando el actor aparece como albañil trabajando en un techo a cielo abierto o con un traje guardavidas en una playa-, otros claramente transitados, como aquel en el que narra los movimientos de sus compañeros de trabajo dentro de un ámbito tan conocido como detestado.

$\mathrm{Al}$ hacer partícipe al público de la rebelión individual, la obra y la película sostienen una larga enumeración de los almuerzos típicos de los oficinistas en los "bares americanos”, los lugares de menú fijo de la época:

NÉSTOR: Ya están por rajar al bar americano... Si no se apuran se quedan sin asiento... (Acomodándose morosamente) y yo morfando en la cama... ¡Y en camiseta! (...) ¡Todos en el mostrador, codo contra codo! (Haciendo la acción) ¡Cortás y chocás! ¡Cortás y chocás! (...) ¿Qué hiciste de comer? (MARTA igual [no responde]) Está bien, está bien... icalladita! Mientras no haya salchicha con puré... o dos chorizos con ensalada (Ligeramente preocupado) 0 pecetoalhornoconpapas (Más preocupado) ¡0 milanesaconpapasfritas! (Preocupadísimo, muy rápido) ¡Bifeconensalada! ¡Matambreconensaladarusa! ¡Jamóncocidoconpickles! (Incorporándoese y apretándose contra el respaldo. Con pánico,) ¡Colchóndearvejas! ¡Tortillaespañola! ¡Panquequedulceleche! ¡Flanconcrema! ¡Duraznoenalmíbar! ¡Mandarinamanzananaranja! (Talesnik, 1967, p. 25-26).

Con el objetivo de establecer una identificación emocional con el protagonista, a partir de la mención a un menú conocido por cualquier espectador que haya comido alguna vez en sitios de esta clase, la repetición de los platos propone un tratamiento que los convierte en mero lenguaje, en significantes vacíos. En la versión cinematográfica, este será el momento más alto de conexión entre las referencias verbales de Vignale y la articulación con el exterior. Aunque se trata de una situación imaginada por el personaje, la puesta en escena fílmica construye el exterior no ya desde un tratamiento subjetivo, sino desde la articulación con unas acciones que ocurren más allá de los límites de la habitación. Los oficinistas efectivamente están comiendo en ese horario, como todos los días. El afuera representado de esta manera para el público intensifica en este su poder de reconocimiento intelectual y afectivo. La fiaca de Ayala convoca, a partir de esta inclusión de una realidad palpable, los mismos sentidos que los directores modernos cuando colocaban a los personajes frente a algún edificio o monumento reconocible: situar a la ficción en el entorno inmediato.

La presencia de Peralta (Jorge Rivera López) en el departamento de Vignale motiva una secuencia en la que lo teatral y lo cinematográfico se complementan y superponen, en función del cruce entre la realidad y el mundo subjetivo objetivado en escena. El baile del "fostro", el juego de los pistoleros que Vignale establece con su compañero de trabajo y la fantasía de Peralta como cantor proponen acciones en las que la ficción dentro de la ficción produce una teatralidad explícita en la pantalla.

Los movimientos de Briski -según indica la didascalia del texto dramático- se asemejan a los de "los chicos cuando juegan solos: realizando todas las acciones, diferenciando cada personaje y ocupando las supuestas posiciones con las actitudes correspondientes" (Talesnik, 1967, p. 31). Sus gestos exagerados, típicos de quien imita una acción, exhiben, ante la atenta mirada de Peralta, una escena al interior de otra mayor o, en el caso del filme, la aparición subrepticia de un momento de teatro (Tesson, 2012) captado por la cámara.

Ayala adhiere a la expresividad mímica del actor una transformación del espacio: la habitación se desvanece; mediante un raccord de movimiento, el juego se 
instala en el patio de la casa del protagonista cuando era un niño. Lo mismo sucede cuando el personaje interpretado por Rivera López -al igual que Pepe Novoa en la puesta original- agarra un escobillón para recobrar su fantasía infantil de verse como cantante: el ámbito real desaparece mientras el actor es filmado en una especie de escenario, iluminado por un reflector, mientras ofrece su espectáculo a un público imaginario. En ambos casos, el montaje y la mutación espacial proveen unos recursos cinematográficos que dialogan con lo teatral de la situación que implica presentar a dos hombres adultos fantaseando, reconstruyendo con sus propios cuerpos un mundo ya perdido.

A continuación de esta secuencia, que establece la máxima imbricación de lo teatral y lo cinematográfico, la puesta ideada por Ayala optará por hacer prevalecer los recursos específicos del medio, opacando o buscando ocultar la procedencia escénica que antes se había colocado en primer plano. Es como si desde este punto las imágenes hubieran llegado a una zona límite de hibridación y debiera reconducirse la narración mediante el empleo de procedimientos cinematográficos.

Como primera medida de alejamiento, en la película se reconfiguran las coordenadas espaciales. Abandonando el encierro de la primera parte, el protagonista pasa a ocupar el espacio público, a transitar por la ciudad. A diferencia de lo que ocurría en una película como Los de la mesa 10 (Simón Feldman, 1960, basada en la obra de homónima de Osvaldo Dragún), en La fiaca no hay deambular ni dispersión en las acciones, dado que estas permanecen como una concatenación de momentos puntuales de intensidad dramática. Pero, así como este rasgo parecería acercarla a los parámetros clásicos de narración, la relación de Vignale con el espacio se presenta siguiendo las pautas previstas dentro del programa de la modernidad.
Carlos Losilla (2012) señala que una de las características mayores del cine moderno se basa en "el desajuste entre el personaje y el decorado y, en consecuencia, entre las distintas escalas del plano" (p. 20). La disposición del protagonista con relación al entorno aparece en $L a$ fiaca al mostrar este tipo de discordancia: Vignale es demasiado pequeño, recortado contra el fondo de unos edificios de dimensiones monstruosas. "Ayala enfrenta al actor en el espacio”, apunta María Valdéz (2005), “y los espacios, aparentemente claros y distintos del espectro de la clase media, se vuelven cárcel para el hombre insatisfecho" (p. 293). Entonces, más allá de integrar la ficción a unas coordenadas topográficas reconocibles, la puesta en escena marca la irresoluble opresión del entorno.

Deleuze (1984) afirma que uno de los síntomas de la crisis de la imagen-movimiento se verifica en la medida en que emerge en el relato una toma de conciencia de los tópicos (p. 292). Si bien este autor se refiere a una instancia histórica precisa (la crisis de la narración clásica propiciada tras el fin de la segunda guerra mundial), esta característica permite confirmar la filiación moderna de La fiaca. Junto con la asunción de situaciones dispersivas y la tematización de un velado deambular sin rumbo del protagonista, que recuerda a la forma de vagabundeo preconizada por Deleuze, el desnudamiento de los tópicos permite incluir a la película de Ayala dentro de las formas que buscan cuestionar los alcances de la imagen-acción.

Desde un primer momento, la transformación del listado de comidas en elementos carentes de significado, en puros efectos de la enunciación (de ahí el hecho de que, al ser mencionadas, las palabras tiendan a unificarse, haciendo que su capacidad evocadora se torne opaca), la apuesta de Talesnik -amplificada por Ayala- logra su cometido de poner en entredicho los sentidos aceptados. Una idéntica función actualiza la larga serie de lugares comunes que expresa la madre del protagonista, con frases como "iNadie

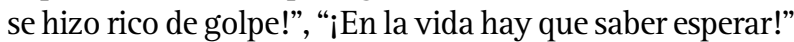
o “iCon voluntad siempre se llega!” (Talesnik, 1967, p. 23). 
Este procedimiento de enumeración se repite con mayor énfasis en la segunda mitad de la película.

El encuentro con Jáuregui (Juan Carlos Gené), el responsable de Recursos Humanos de Fiagroplast, representa un momento clave de enfrentamiento entre los tópicos -formulados por un personaje que encarna un discurso institucionalizado- con relación a la impugnación que la fiaca de Vignale significa para la sociedad. A la sucesión de palabras emitidas para el resguardo de los mandatos sociales, el protagonista responde con imágenes que recuperan recuerdos de infancia. En ellos, Vignale escribe en el pizarrón "el ocio es la madre de todos los vicios", forma fila en un acto escolar o bien escucha la misma serie de dichos vacíos pronunciados por sus maestros. La voz de Jáuregui continúa, mientras en la banda visual la iconografía de los próceres nacionales -Sarmiento, San Martín, Belgrano- aparece confusamente mezclada con las fotografías más cercanas de Perón, Juan Manuel Fangio, Palito Ortega, entre muchas otras, expuestas a gran velocidad. A partir de la discordancia entre las palabras escuchadas y lo visual, la narración efectúa un comentario explícito que tiende a impugnar tanto al discurso como a estos "símbolos nacionales", al convertirlos en imágenes carentes de espesor, en estampitas.

Las escenas finales marcan un punto de despegue de lo teatral a partir de una inclinación realista. En los escenarios, el desenlace se producía con la aparición del gerente de Fiagroplast blandiendo un sándwich ante la mirada famélica del protagonista. Este personaje decisivo en la resolución del conflicto casi no hablaba, solo se limitaba a mostrar el alimento convertido en objeto de deseo. La transformación de un elemento profano en símbolo derriba el realismo y da paso al predominio de lo alegórico. En su pasaje al cine, Ayala opta por tomar distancia de esta causalidad implícita (Dubatti, 1989) que constituye uno de los rasgos innovadores de la obra de Talesnik con relación al realismo teatral de los sesenta.
En el filme, la clausura narrativa posee una lógica más claramente referencial. La derrota de Vignale -sumada a la de Perales que, a diferencia de la obra, aquí lo secunda en su decisión- se explicita mediante la pérdida de todo: su esposa lo abandona, debe devolver los electrodomésticos comprados en cuotas, gasta sus últimos centavos. Imaginándose como un linyera, como un faquir -según lo que Marta le predice antes de dejarlo- el protagonista decide cesar en su rebeldía mostrándose evidentemente abatido.

El epílogo muestra a los personajes retornando a sus tareas habituales, sintetizadas en la mirada final del protagonista desolado. Son estas decisiones las que probablemente hayan hecho afirmar a la mencionada crítica de La Nación que en la película se optó por el camino del realismo. Como pudo verse, esta opción por un tipo de registro no fue unidireccional. El realismo en la película estuvo asediado de manera constante por factores encaminados hacia otros territorios lejanos.

\section{Conclusiones}

A finales de los sesenta, el impulso modernizador que caracterizó esta época se encontraba en una instancia de recambio. Visiblemente agotados, algunos de los mecanismos que fueron sus principales banderas de autoafirmación -la opción por un realismo de nuevo cuño, el papel otorgado a los jóvenes dentro de los relatos, la negación a otorgar soluciones inmediatas o tranquilizadoras- tendieron a difuminarse en las narraciones cinematográficas y teatrales. Sumado a esto, las políticas constrictivas del gobierno militar del general Juan Carlos Onganía terminaron por desplazar estas preocupaciones hacia los márgenes. En este marco, un director como Ayala, ferviente defensor del carácter industrial y comercial del cine, se había mantenido en pie gracias a un tipo de cine de fácil captación y sin mayores innovaciones. Fue esta la época de películas sobre hoteles alojamiento, pero también de otras como Martín Fierro (1968), en la que Torre Nilsson ensayó un cambio drástico de su orientación autoral. 
En este contexto, en cierto modo sombrío para la modernidad, el estreno teatral de La fiaca abrió una vía inexplorada a través de la cual podía intersectarse el compromiso con la realidad con el entretenimiento y la risa. Ayala captó rápidamente esto, al entender que con su reescritura podía alcanzar nuevamente el cruce entre calidad y masividad que desde siempre le interesaron. Entonces, lejos de la consagración horizontal (Terán, 1991) que significó para los cineastas noveles de principios de los sesenta ampararse en la producción escénica de unos teatreros también ignotos, el éxito de la versión escénica fue un acicate, una apuesta que la pantalla debía redoblar. El sustento (e incluso la amplificación) de la locura desatada en el cuerpo del protagonista constituyó, más allá de las particularidades textuales analizadas, el principal atractivo del espectáculo cinematográfico ofrecido al público.

Al referirse a la puesta teatral, Pellettieri (1997) considera que en La fiaca "ya se ha atenuado la ortodoxia realista, aunque la rebelión de Néstor Vignale todavía funcione de manera ilusionista, sin 'deformaciones', monólogos interiores ni abolición del tiempo objetivo" (p. 137). Ayala profundiza con su película la distancia con el realismo, entendido como trozo de vida incorporando al relato un conjunto de elementos que buscan trascenderlo mediante una doble vía: por la aparición de la subjetividad directa y, asimismo, por apelar a comentarios puntuales encargados de impugnar o ironizar sobre la veracidad de aquello que está siendo visto o escuchado. Como obra de síntesis, el filme amalgama los procedimientos empleados en otras traslaciones anteriores - los desplazamientos urbanos, el abierto reconocimiento del rodaje en estudios, la representación en abismo- a los que suma otros basados en el distanciamiento irónico con relación a los saberes aprehendidos.
En Pasen y vean, el libro de entrevistas que repasa su propia obra, Leonardo Favio rememora la siguiente anécdota sobre el origen de su versión de Juan Moreira (1971):

Un día, caminando por Carlos Pellegrini, me encontré con Fernando Ayala y me invitó a tomar una cerveza. Inmediatamente pensé: éste es Aries Cinematográfica, aquí hay guita. Me preguntó en qué andaba, y en el aire inventé que estaba embalado con una historia que era para ganar mucha plata, le dije como haciéndome el distraído. A ver si picaba ¿no? Juan Moreira le dije [...] Al día siguiente me llamó diciéndome que Héctor Olivera me quería ver (citado en Schettini, 1995, p. 122).

El recuerdo de este encuentro grafica una relación necesaria, obligatoria, con el dinero, puesta en boca de un cineasta que buscó de forma denodada edificar una obra popular. La fiaca fue una de las piedras angulares que determinaron el cambio de rumbo de toda una plana de directores iniciados en los sesenta. En las postrimerías de la década, estos comenzaron a manifestar una preocupación referida a la llegada masiva de sus obras, sin renunciar por ello a un reconocimiento artístico.

Si en un principio la discusión instalada por Torre Nilsson enfrentó la expresión con el espectáculo, esta película trazó un rumbo posible, como quedó demostrado, al condensar con resultados felices - esto es, económicamente rentables y estéticamente valiosos- ambas posibilidades en una sola. En muchos sentidos, películas posteriores como Juan Moreira, Nazareno Cruz y el lobo (Favio, 1973), Los chantas (José Martínez Suárez, 1975) o Los gauchos judios (Juan José Jusid, 1975) son deudoras del espíritu, al mismo tiempo artístico y comercial, prohijado por ese "tío" que fue Fernando Ayala. 


\section{Referencias}

Abuín González, A. (2012). El teatro en el cine. Estudio de una relación intermedial. Madrid, España: Cátedra.

Aumont, J. (2012). El cine y la puesta en escena. Buenos Aires, Argentina: Colihue.

Barthes, R. (1974). El placer del texto. Buenos Aires, Argentina: Siglo XXI.

Bourdieu, P. (1991). La distinción. Criterios y bases sociales del gusto. Madrid, España: Taurus.

Bourdieu, P. (1992). Las reglas del arte. Génesis y estructura del campo literario. Barcelona, España: Anagrama.

Cattrysse, P. (1992). Pour une théorie de l'adaptation filmique. Le film noir américain. Bern, Suiza: Lang.

Deleuze, G. (1984). La imagen-movimiento. Estudios sobre cine 1. Barcelona, España: Paidós.

Dubatti, J. (1989). Ricardo Talesnik y el realismo. La fiaca (1967). En 0. Pellettieri (Comp.), Teatro argentino de los '60: Polémica, continuidad y ruptura (pp. 157-168). Buenos Aires, Argentina: Corregidor.

España, C. (2005). Transformaciones. Cine argentino 19571983: modernidad y vanguardias. En C. España (Dir.), Cine argentino. Modernidad y vanguardias. 1957-1983, Volumen I (pp. 20-207). Buenos Aires, Argentina: Fondo Nacional de las Artes.

Font, D. (2002). Paisajes de la modernidad. Cine europeo, 1960-1980. Barcelona, España: Paidós.

Gesternkorn, J. (1994). Lever le Rideau. En C. Hamon-Siréjols, J. Gestenkorn, y A. Gardies (Eds.), Cinéma et théâtralité (pp. 13-27). Lyon, Francia: Aléas.

Gramsci, A. (1981). Cuadernos de la cárcel. México D.F., México: ERA. (Trabajo original publicado en 1930)

Kristeva, J. (1978). Semiótica 1. Madrid, España: Fundamentos.

Losilla, C. (2012). La invención de la modernidad o cómo acabar de una vez por todas con la historia del cine. Madrid, España: Cátedra.

Martínez, T. E. (1961). La obra de Ayala y Torre Nilsson en las estructuras del cine argentino. Buenos Aires, Argentina: Ediciones Culturales Argentinas.

Miller, K. (2014). La experiencia del vacío: Tedio y política en novelas argentinas del 2000. Revista lberoamericana, 80(247), 677-692. doi:10.5195/reviberoamer.2014.7174

Mudrovcic, M. E. (2010). Nombres en litigio. Las guerras culturales en América Latina. Del Happening desarrollista a la posguerra fría. Rosario, Argentina: Beatriz Viterbo.

Oubiña, D. (2016). Una política de autores para Latinoamérica. (Nuevos cines y nueva crítica: Argentina, Brasil, México en los sesenta). Kamchatka, 8, 347-361. Recuperado de https://ojs.uv.es/index.php/kamchatka/article/view/9022

Pellettieri, 0. (1997). Una historia interrumpida. Teatro argentino moderno 1949-1976. Buenos Aires, Argentina: Galerna.

Pérez Bowie, J.A. (2003). La teoría sobre la adaptación cinematográfica de textos literarios. Estado de la cuestión. En J.A. Pérez Bowie (Ed.), La adaptación cinematográfica de textos literarios. Teoría y práctica (pp. 11-30). Salamanca, España: Plaza Universitaria.

Potenze, J. (1 de octubre de 1967). Festival Briski en el San Telmo. La prensa, p 21.

Prohibida La fiaca. (20 de enero de 1969). Siete días, 2(89), p. 54

Rapallo, A. (1993). Fernando Ayala. Buenos Aires, Argentina: Centro Editor de América Latina.

Schettini, A. (1995). Pasen y vean. La vida de Favio. Buenos Aires: Argentina, Sudamericana.

Talesnik, R. (1967). La fiaca. Buenos Aires, Argentina: Talia.

Terán, 0. (1991). Nuestros años sesenta. La formación de la nueva izquierda intelectual en la Argentina 1956-1966. Buenos Aires, Argentina: Puntosur. 
Tesson, C. (2012). Cine y teatro. Barcelona, España: Paidós. Torre Nilsson, L. (1985). Torre Nilsson por Torre Nilsson. Buenos Aires, Argentina: Fraterna.

Valdéz, M. (2005). Fernando Ayala. Cultor de la crónica y de la actualidad. En C. España (Dir.), Cine argentino. Modernidad y vanguardias 1957-1976 (pp. 272-299). Buenos Aires, Argentina: Fondo Nacional de las Artes.

Versión fílmica bien lograda de La fiaca. (7 de marzo de 1969). La Nación, p. 23

Williams, R. (1994). Cultura. Sociología de la comunicación y del arte. Barcelona, España: Paidós.

Filmes:

Aletti, G., Rodríguez Mentasti, M., Salías, S., Stevani, C. (Productores), y Mugica, R. (Director). (1965). El reñidero [Película]. Argentina: Sono Film.

Ayala, F. (Productor \&t Director), Olivera, H. (Productor). (1963). Paula cautiva [Película]. Argentina: Aries Cinematográfica.

Ayala, F. (Productor \& Director), Olivera, H. (Productor). (1968). Psexoanálisis [Película]. Argentina: Aries Cinematográfica.

Ayala, F. (Productor \& Director), Olivera, H. (Productor). (1969). La fiaca [Película]. Argentina: Aries Cinematográfica.

Ayala, F. (Productor \& Director), Olivera, H. (Productor). (1970). La guita [Película]. Argentina: Aries Cinematográfica.

Ayala, F. (Productor \&t Director), Olivera, H. (Productor). (1971). Los neuróticos [Película]. Argentina: Aries Cinematográfica.

Báilez, H.. (Productor), y Martínez Suárez, J. (Director). (1975). Los chantas [Película]. Argentina: Cinematográfica Victoria.
Barreto, L. (Productor), y Diegues, C. (Director). (1980). Bye Bye Brasil [Película]. Brasil: Luiz Carlos Barreto produções cinematográficas.

Cahen Salaberry, E. (Productor \& Director). (1978). jYo también tengo fiaca! [Película]. Argentina: Cinematográfica Victoria.

Cimonetti, M. (Productor), y Feldman, S. (Director). (1960). Los de la mesa 10 [Película]. Argentina: Siluetas.

Daly, J., Gibson, D., Hurd, G. (Productores), y Cameron, J. (Director). (1984). Terminator [Película]. Estados Unidos: Hemdale-Pacific Western-Euro Film Funding-Cinema '84-Greenberg Brothers Partnership.

Favio, L., (Productor \&t Director), Sires, J., Tarantini, A., y Labraña, H. (Productores). (1973). Juan Moreira [Película]. Argentina: Choila Producciones.

Favio, L., (Productor \& Director), y De Benedetti, O. (Productor). (1974). Nazareno Cruz y el lobo [Película]. Argentina: Centauro Films.

Gaffet, N., Pereira, P., Sires, J. (Productores), Torre Nilson, L. (Productor \& Director). (1961). La mano en la trampa [Película]. Argentina: Producciones del Ángel.

Lovell, D., Prophet, M., Roos, F. (Productores), y Coppola, F. (Director). (1984). Cotton Club [Película]. Estados Unidos: Zoetrope Studios-Producers Sales Organizacion-Totally Independient-Robert Evans Company.

Parrilla, C. (Productor), y Martínez Suárez, J. (Director). (1960). El crack [Película]. Argentina: Alithia Cinematográfica.

Rodríguez Mentasti, E. (Productor), y Mugica, R. (Director). (1961). El centroforward murió al amanecer [Película]. Argentina: Sono Film.

Rodríguez Mentasti, E. (Productor), y Torre Nilson, L. (Director). (1957). La casa del ángel [Película]. Argentina: Sono Film.

Torre Nilson, L. (Productor), y Jusid, J.J. (Director). (1975). Los gauchos judios [Película]. Argentina: Films Cuatro. 